\title{
OS EFEITOS DO ESPRAIAMENTO DAS INDÚSTRIAS DA REGIÃO METROPOLITANA DE SÃO PAULO SOBRE O TERRITÓRIO DO INTERIOR PAULISTA
}

\author{
Rogerio Tineu*
}

\section{RESUMO}

A desconcentração industrial da RMSP - Região Metropolitana de São Paulo - é objeto de diversas pesquisas bem, como o estudo dos efeitos causados por essa desconcentração sobre o território nacional. Este trabalho, em particular, limita-se a estudar os efeitos decorrentes da desconcentração industrial a partir do início da década de 1990 sob a forma de um espraiamento das indústrias para o entorno da RMSP, especificamente, as Regiões Administrativas de Campinas, Sorocaba e São José dos Campos.

\section{PALAVRAS-CHAVE:}

desconcentração industrial, economia paulista, espraiamento industrial.

\section{ABSTRACT}

The industrial desconcentration of São Paulo metropolitan region is object of several searches as well as the study of the effects of this on the national territory. This work, in particular, is confined to study the effects of industrial desconcentration from the beginning of the 1990s in the form of a dispersion of industries to the surroundings of São Paulo metropolitan region, specifically, the townships of Campinas, Sorocaba and São José dos Campos.

\section{KEYWORDS:}

industrial desconcentration, paulista economy, industrial dispersion.

\section{Introdução}

O objetivo deste estudo é identificar e caracterizar os principais efeitos e relações da desconcentração industrial da Região Metropolitana de São Paulo (RMSP) sobre as Regiões Administrativas (RA 's) de Campinas, São José dos Campos e Sorocaba no período de 1990 a 2005.

O fenômeno chamado espraiamento das indústrias da RMSP move-se em direção dessas RA's e foi motivado pela busca de custos menores e de uma operação mais eficiente das empresas, o que provocou o desenvolvimento industrial das RA's citadas e intensificação das relações econômicas, sociais e empresariais entre a RMSP e as RA's.
Portanto, como problema de pesquisa foi elaborada a seguinte pergunta: Quais os elementos que propiciaram o processo de descontração da RMSP e seus efeitos sobre as RA's de Campinas, São José dos Campos e Sorocaba como consequência desse processo?

O estudo dos motivos pelos quais o processo de desconcentração industrial ocorreu é fundamental para a compreensão, identificação e análise dos seus efeitos sobre o território do interior do estado de São Paulo na forma de um espraiamento urbano e industrial.

A identificação das relações e forças que se estabelecem a partir de uma nova configuração do território apresenta-se relevante para o planejamento e tomada de decisões na esfera pública ou privada no estado de São Paulo. 
O presente estudo consiste, basicamente, na seleção, organização, tratamento e análise de alguns indicadores socioeconômicos que comparam as regiões, o estado de São Paulo e os seus respectivos setores industrial, de comércio e de serviços.

Os indicadores selecionados foram os seguintes: PIB (Produto Interno Bruto), VTI ${ }^{1}$ (Valor de transformação Industrial, VAF $^{2}$ (Valor Agregado Fiscal), consumo de energia elétrica em megawat hora (MWh), número de estabelecimentos empresariais e pessoal ocupado. Os dados em sua totalidade foram extraídos do site da FUNDAÇÃO SISTEMA ESTADUAL DE ANÁLISE DE DADOS - SEADE e do livro Economia Paulista de Wilson Cano.

\section{Fatores que motivaram a desconcentração industrial da região metropolitana de São Paulo}

A desconcentração industrial da Região Metropolitana de São Paulo (RMSP) teve suas origens na segunda metade dos anos $1970 \mathrm{com}$ o II Plano Nacional de Desenvolvimento (II PND). Esse Plano estimulou a criação de diversos investimentos e pólos industriais no território nacional com o objetivo de deslocar os investimentos produtivos e o crescimento econômico do eixo Rio - São Paulo às regiões mais carentes e menos desenvolvidas do Brasil. São exemplos do deslocamento desses investimentos: Fiat em Betim (MG), as siderúrgicas Açominas (MG), Tubarão (ES) e Itaqui (MA), o pólo petroquímico de Camaçari (BA), Carajás (PA), entre vários outros.

De acordo com NOBRE $(2007$, p. 3) os outros dois fatores que contribuíram para a desconcentração industrial da RMSP foram a perda de sua vantagem comparativa e a expansão da infraestrutura do interior paulista.

Esses fatores podem ser desmembrados em diversos outros e podem ser agrupados sob o ponto de vista espacial, ou seja, existe um conjunto de fatores intrínsecos à RMSP e outro conjunto de fatores localizados no interior do estado de São Paulo ou, simplesmente, externos à RMSP.

O conjunto de fatores que contribuíram para a desconcentração industrial da RMSP e, ao mesmo tempo, para o espraiamento de suas indústrias no sentido do interior foi descrito por diversos autores como CANO (2007), NOBRE (2007), AZZONI (1987), AZZONI (1993), ARAÚJO (2001) e compilados conforme segue.

Os fatores intrínsecos à RMSP que propiciaram a perda de sua vantagem comparativa para outras áreas do território nacional, fundamentalmente para as cidades do interior do estado de São Paulo, são os seguintes:

a) crescimento rápido e caótico que se refletiu em um tráfego moroso que por vezes prejudicava a logística das empresas; b) a legislação ambiental que forçou a instalação das plantas fabris em outras cidades com menores exigências ambientais; c) custo operacional elevado em função da forte organização sindical, o que elevou os salários e benefícios dos trabalhadores da região metropolitana de São Paulo; d) desestruturação das cadeias produtivas, pois para uma produção baseada no modelo flexível (e não mais fordista) eram necessários, dentre outros requisitos, a proximidade geográfica dos principais fornecedores de uma determinada indústria (como é o caso da automobilística, petroquímica, química ou moveleira) para que o fornecimento de peças, componentes e matériaprima seguissem rigorosos planos de entrega de acordo com o planejamento de produção das indústrias a fim de diminuir drasticamente os seus estoques, o chamado sistema just in time; e) a obsolescência dos parques fabris instalados há décadas na RMSP também influenciaram na decisão de investir em novas instalações em localidades que oferecessem custos operacionais menores.

Sob a condição de fatores externos à RMSP podem ser citados: a) guerra fiscal com a diminuição ou isenção de impostos municipais (ISS e IPTU) e estaduais (ICMS), além de doações e concessões de terrenos para a instalação das fábricas, o que diminuía o custo operacional das 
indústrias; b) melhoria da infra-estrutura rodoviária, aeroviária (aeroporto de Viracopos) e de telecomunicações das regiões administrativas de Campinas, São José dos Campos e Sorocaba, cujos municípios, por sua vez, guardavam pouca distância da RMSP; c) outro ponto de destaque do interior paulista é com relação à produção de combustíveis, $100 \%$ da produção do álcool combustível está localizada no interior e 95\% dos combustíveis derivados do petróleo; d) intenso desenvolvimento tecnológico das RA's citadas, principalmente na região de São José dos Campos com o ITA (Instituto Tecnológico da Aeronáutica) e UNESP (Universidade Estadual de São Paulo "Julio de Mesquita Filho") com a Faculdade de
Engenharia de Guaratinguetá, além de outras instituições privadas de ensino superior, na região de Campinas com a UNICAMP (Universidade Estadual de Campinas), O IAC (Instituto Agronômico de Campinas), ESALQ - Escola Superior de Agricultura "Luiz de Queiroz" da Universidade de São Paulo, PUC Campinas e demais instituições privadas de ensino superior. Lembrando que o pólo tecnológico de Campinas dista cerca de cem quilômetros de outro importante pólo tecnológico, o da cidade de São Carlos (esta pertencente à Região Administrativa Central) na qual estão instaladas a UFSCAR (Universidade Federal de São Carlos) e o campus da USP (Universidade de São Paulo).

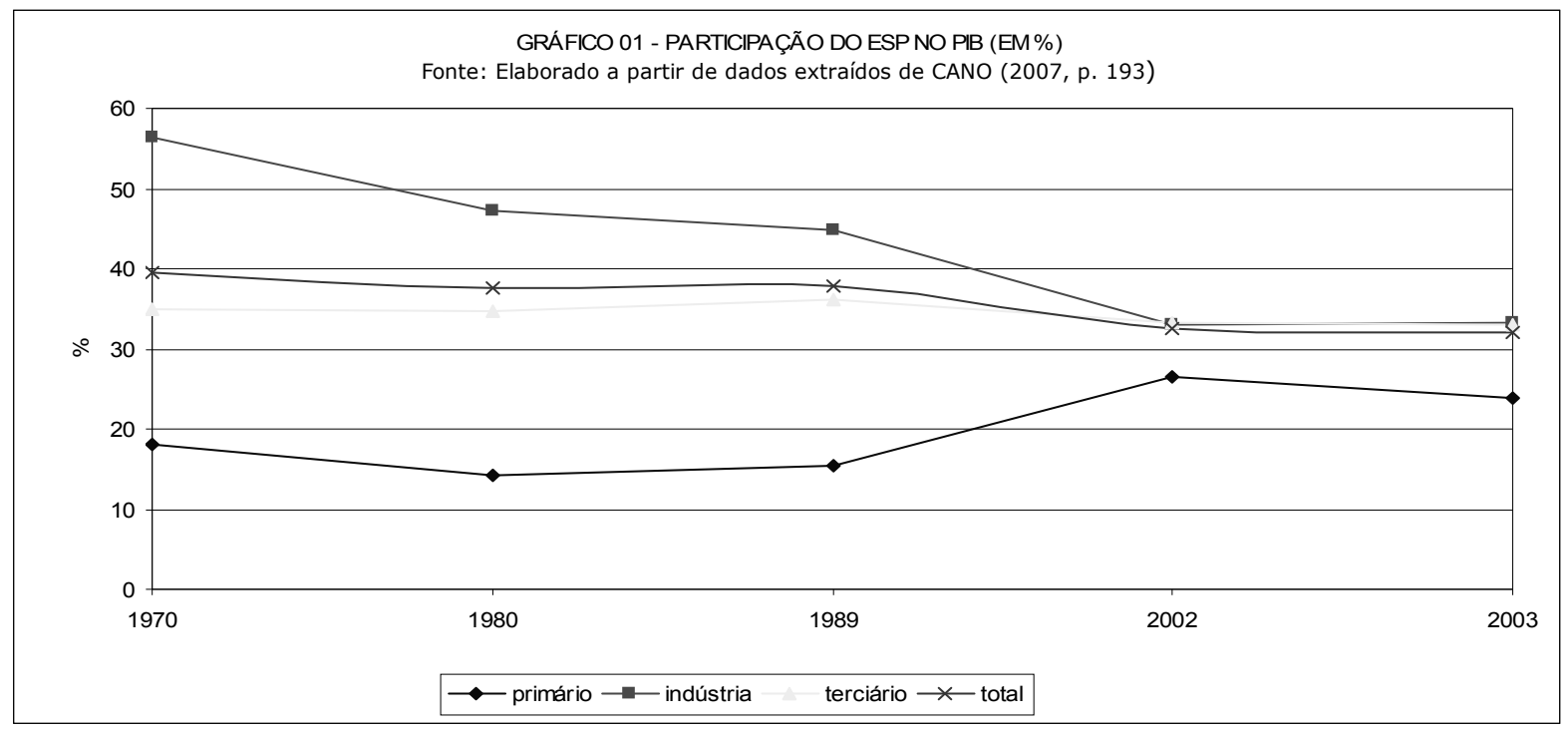

Ambos os conjuntos de fatores da desconcentração espacial da indústria, intrínsecos e externos à RMSP, propiciaram um fenômeno denominado de espraiamento da indústria paulista a partir da RMSP. Muito embora, de acordo com NOBRE (2007, p. 4) a desconcentração industrial não foi uniforme e ocorreu de forma espraiada, num raio de $150 \mathrm{~km}$ a partir do marco zero da capital paulista. Seguindo o eixo das principais rodovias do estado, em direção a Campinas e região, pelo complexo rodoviário Anhanguera-Bandeirantes e mais adiante atingindo as cidades de São Carlos e de Ribeirão Preto. A região de Sorocaba, no eixo da rodovia Castelo Branco; Vale do Paraíba pelo complexo rodoviário Dutra, Airton Sena e Carvalho Pinto, lembrando que a região do Vale do Paraíba liga-se a Campinas pela rodovia Dom Pedro.

Os gráficos e dados descritos a seguir mostram, a partir da década de 1970, a diminuição da participação do estado de São Paulo no PIB nacional e, ao mesmo tempo, a desconcentração industrial da RMSP e aumento 
da industrialização das RA's de Campinas, São José dos Campos e Sorocaba.

O gráfico 01 apresenta o declínio da participação do estado de São Paulo no PIB nacional. Na década de 1970 a participação era de $39,5 \%$ e tendo um pequeno declínio nos anos 80 e chega a $32,1 \%$ no ano de 2003 .

Já o PIB do setor agropecuário paulista cresce substancialmente tendo uma participação de $18 \%$ em 1970 e chegando a $23,9 \%$ no ano de 2003. O inverso ocorreu com a indústria paulista que no ano de 1970 obteve uma participação no PIB nacional da produção industrial da ordem de $56,4 \%$ sendo declinante no início dos anos 80 e 90 (47,3\% e $44,7 \%$ respectivamente), chegando a um terço no ano de 2003 . Ou seja, a produção industrial do estado de São Paulo teve sua participação no PIB nacional reduzida pela metade em um período de 30 anos. O setor terciário se manteve relativamente estável durante o período de 1970 até 2003.

Em relação à desconcentração espacial da indústria paulista e sua participação regional no
VTI (valor de transformação industrial) o gráfico 02 mostra, no período de 1970 a 2003, o aumento do VTI do Brasil excetuando-se o estado de São Paulo e o declínio do VTI do estado de São Paulo.

Os dados do VTI para a RMSP são declinantes (43,5\% em 1970 para $16,8 \%$ em 2003), o que demonstra sua desconcentração industrial, e ao mesmo tempo o VTI do interior do estado quase dobrou, em 1970 o VTI foi de 14, 7\% e em 2003 chegou a $27 \%$.

Para a análise do VAF (valor agregado fiscal) é notório o declínio da indústria da RMSP em detrimento das regiões administrativas de Campinas, São José dos Campos e Sorocaba (ver gráfico 03). A RMSP teve declínio de seu VAF de 64,38\% (1980) para 38,3\% (2003), a RA de Campinas teve um aumento do VAF 1980 de $15,16 \%$ para $26,76 \%$ no ano de 2003 . A RA de São José dos Campos dobrou o seu VAF industrial no período analisado, sendo em $19805 \%$ e em 2003 chegou a 10,75\%. Os resultados da RA de Sorocaba também foram elevados: $3,98 \%$ em 1980 , e $5,61 \%$ em 2003.

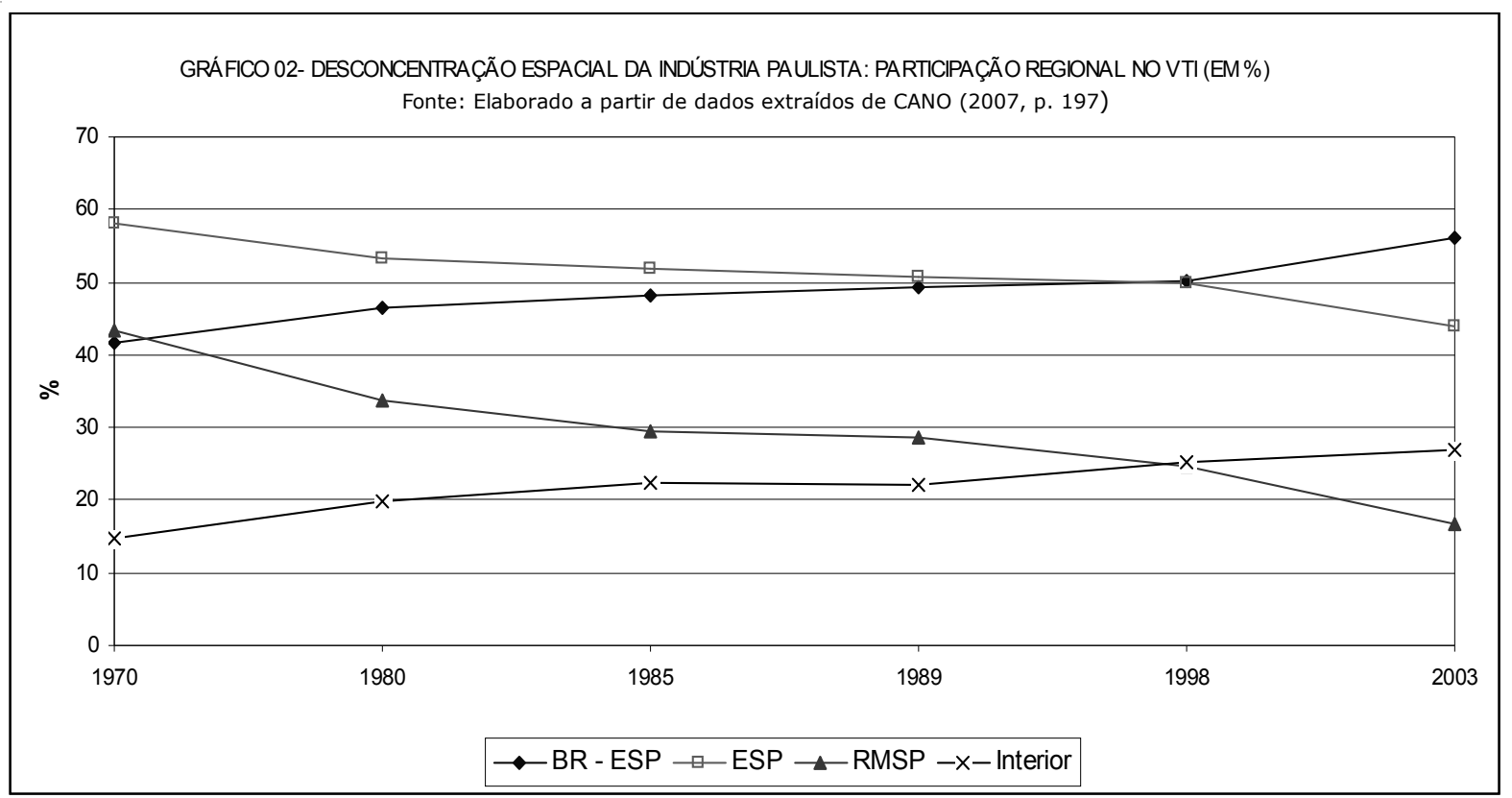




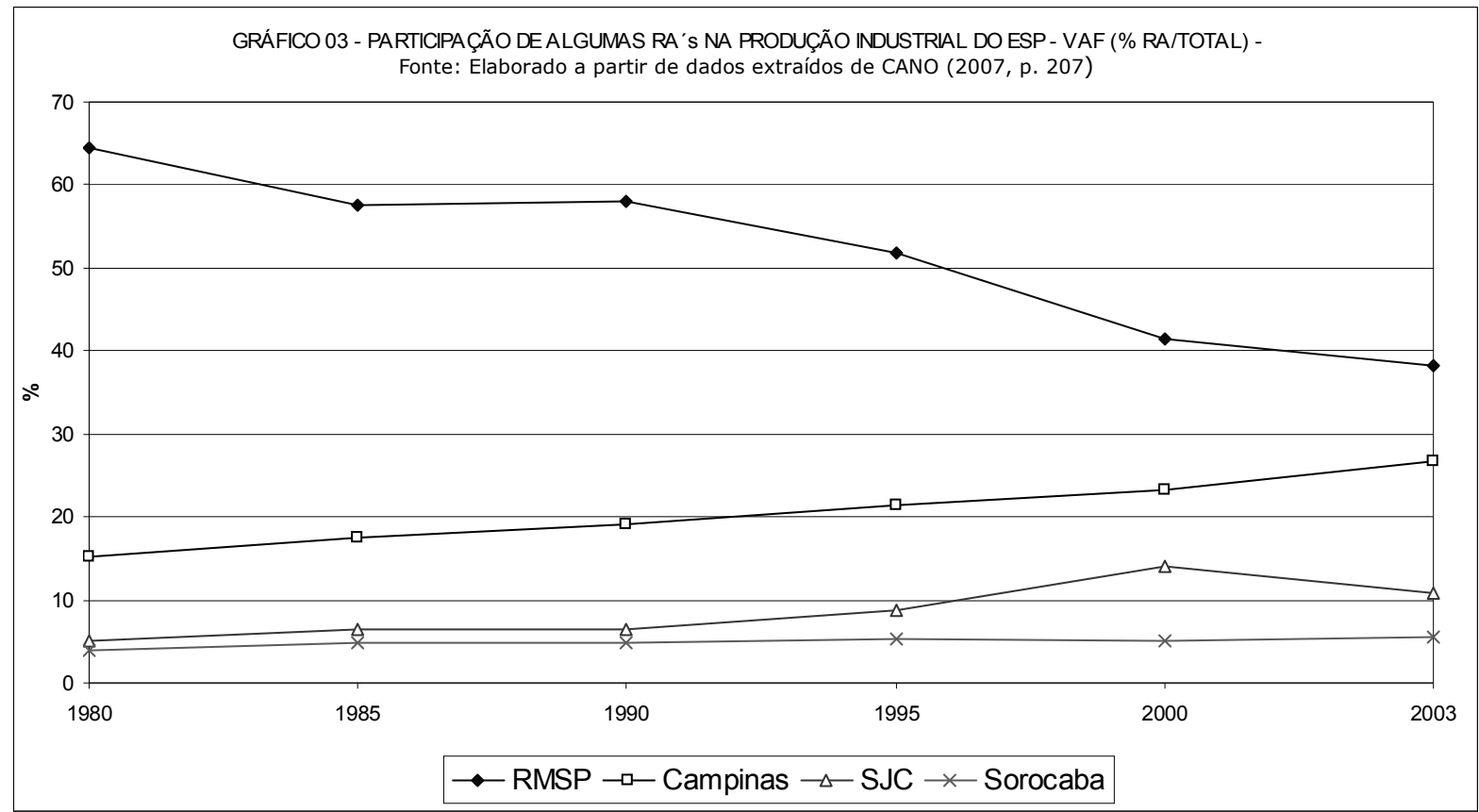

Com relação ao processo de concentração e desconcentração industrial da RMSP e sua importância como pólo econômico, LENCIONE (1994, p. 54) afirma o seguinte.

Historicamente, foi a concentração das atividades econômicas, sobretudo a concentração industrial, que estruturou a Região Metropolitana de São Paulo, tornandoa o pólo econômico do país. Mas, embora sejam ainda relevantes os mecanismos de concentração, são os de dispersão os responsáveis pela reestruturação desta Região, que desde os anos 70 conhece um processo significativo de expansão atingindo o Interior.

Percebe-se, portanto, a relevância do desempenho econômico da RMSP como pólo industrial, pois promoveu uma série de efeitos sobre o território das regiões administrativas mais próximas da RMSP, tanto sob o ponto de vista de sua acumulação como do espraimento do capital na forma de investimentos, conforme descrito no item a seguir.

\section{Efeitos da desconcentração industrial da RMSP sobre as regiões administrativas de Campinas, São José dos Campos e Sorocaba.}

A RMSP representa um pouco mais de $3 \%$ da superfície do estado de São Paulo e nela habita quase metade da população do estado, algo em torno de 20 milhões de pessoas. Juntas, as superfícies das regiões de Campinas, São José dos Campos e Sorocaba representam 34\% do território do estado de São Paulo com uma população aproximada de 11 milhões de habitantes, portanto, somando-se a estas regiões a RMSP tem-se que mais de três quartos da população do estado de São Paulo habitam aproximadamente $37 \%$ de sua superfície gerando $82 \%$ do PIB estadual.

A densidade demográfica das regiões estudadas também sofreu forte variação no período de 1990 a 2005 principalmente nas regiões sob os efeitos diretos do espraiamento. A RMSP tinha em 1990 uma densidade de 1874 habitantes $/ \mathrm{Km}^{2}$ e em 2005 era de 2376 habitantes com uma variação de quase $27 \%$ contra as RA's de Campinas com 
um acréscimo de quase 39\% (157 hab./ $\mathrm{Km}^{2} \mathrm{em}$ 1990 para 218 em 2005), Sorocaba com um acréscimo de $40 \%$ (47 hab./ Km² em 1990 contra 66 em 2005) e São José dos Campos com uma variação de 37\% (134 hab./ Km² em 2005 e 98 em 1990).
O mapa 1 apresenta a localização da RMSP e as regiões administrativas do estado de São Paulo, percebe-se a continuidade das áreas das regiões estudadas sendo que todas as RA's são limitrofes à RMSP.

\section{MAPA 1 - LOCALIZAÇÃO DAS REGIÕES ADMINISTRATIVAS DO ESTADO DE SÃO PAULO}

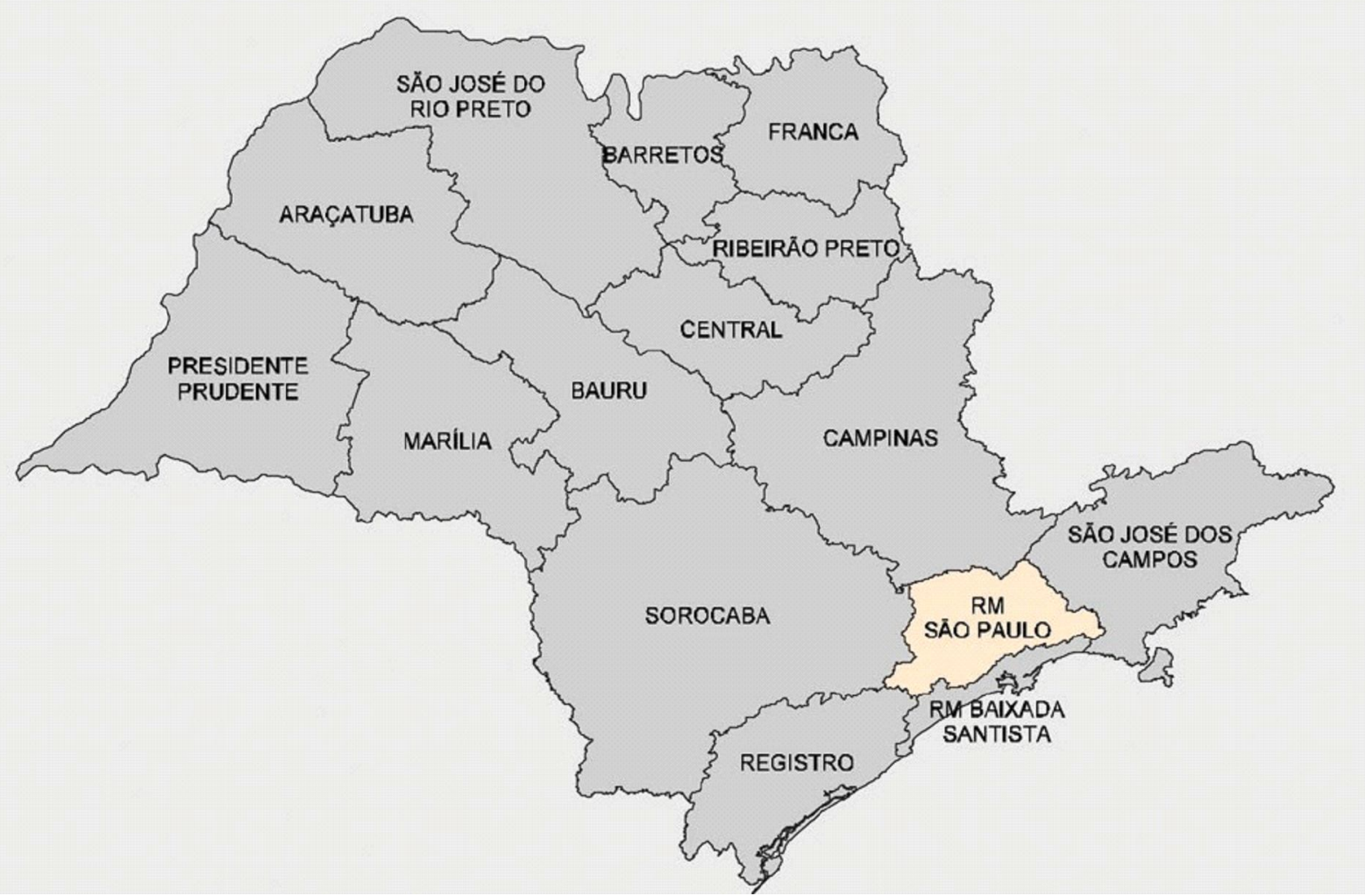

Fonte: IGC - Instituto Geográfico e Cartográfico

O espraiamento da indústria da RMSP provocou efeitos no interior paulista, especificamente nas regiões administrativas de Campinas, São José dos Campos e Sorocaba, que são estudas a partir deste ponto do trabalho.

Uma primeira variável que merece análise é o comportamento do PIB das regiões administrativas (ver tabela 01). O PIB da RMSP em 2002 foi de R\$285 bilhões e em 2005 chegou a $\mathrm{R} \$ 416$ bilhões, uma variação de quase $46 \%$ no período, sendo que o PIB per capita saltou de R\$ 15.392,23 em 2002 para R\$21.465,29 em 2005, uma variação de $39,46 \%$.

Os resultados para as RA's de Campinas e Sorocaba, no mesmo período de análise, superaram o desempenho da RMSP. Campinas teve um incremento do PIB da ordem $49,24 \%$ e o PIB per capita foi de $40,95 \%$, já Sorocaba obteve um acréscimo do PIB de $53,62 \%$ e um PIB per capita de 45,06\%. O mesmo desempenho 
não foi obtido por São José dos Campos tendo uma variação do PIB de 2002 a 2005 da ordem de $28,01 \%$ contra um PIB per capita de $21,31 \%$.

Tanto a RA de Campinas como a de Sorocaba obtiveram um acréscimo da riqueza superior ao total do estado e da RMSP, o inverso ocorreu com a região de Sorocaba.

O número de estabelecimentos do comércio, da indústria e dos serviços por região administrativa é outra importante variável que

\section{TABELA 01}

PI B DAS REGIÕES ADMINISTRATIVAS DO ESTADO DE SÃO PAULO (EM BILHÕES DE REAIS)

\begin{tabular}{|l|r|r|r|r|r|}
\hline RA & 2002 & 2003 & 2004 & 2005 & Var. \% (2005/2002) \\
\hline RMSP & 286 & 325 & 360 & 417 & 45,65 \\
\hline SJC & 29 & 31 & 37 & 38 & 34,01 \\
\hline SOROCABA & 22 & 27 & 98 & 53,62 \\
\hline CAMPINAS & 511 & 86 & 643 & 411 & 427 \\
\hline TOTAL ESP & & 579 & & & 42,27 \\
\hline
\end{tabular}

\section{PI B PER CAPITA DAS REG IÓES ADMI NIST RATIVAS DO ESTADO DE SÃ O PAULO (EM REA IS)}

\begin{tabular}{|l|r|r|r|r|r|}
\hline RMSP & $15.392,23$ & $17.253,62$ & $18.810,35$ & $21.465,29$ & 39,46 \\
\hline SJC & $14.103,21$ & $14.513,24$ & $17.000,62$ & $17.108,51$ & 21,31 \\
\hline SOROCABA & $8.610,56$ & $10.107,38$ & $11.389,40$ & $12.490,52$ & 45,06 \\
\hline CAMPINAS & $13.106,42$ & $14.872,10$ & $16.661,83$ & $18.473,47$ & 40,95 \\
\hline
\end{tabular}

Fonte: Fundação SEADE

possibilita compreender a dinâmica da concentração e da desconcentração industrial no estado de São Paulo. É importante destacar que esta análise é quantitativa e não leva em consideração nem o porte e nem o tipo dos estabelecimentos, mas mostra a existência de uma dinâmica que ora segue um padrão genérico e ora é específica para cada uma das RA's.

A tabela 02 apresenta, para a RMSP, uma variação quase nula do número de indústrias no período de 1991 a 2006, tanto o comércio quanto os serviços obtiveram uma variação positiva de $69 \%$ e $84 \%$ respectivamente. A participação do número de estabelecimentos comerciais do total da RMSP manteve-se estável para o período de análise, ou seja, girou em torno dos $40 \%$. Os estabelecimentos dos serviços tiveram um incremento em sua participação do total da RMSP, em 1991 era de 39\% e chegou a 45\% em 2006. O mesmo não ocorreu com os estabelecimentos industriais que tiveram um declínio acentuado em sua participação do total, o que era em 1991 de $21 \%$ transformou-se em $14 \%$ em 2006.

o comportamento do número de estabelecimentos das RA's de Campinas, São José dos Campos e Sorocaba é muito parecido com o da RMSP, destaque deve ser dado ao incremento do número de estabelecimentos industriais no período $2006 / 1991$ que foi superior aos $38 \%$ para as três RA's analisadas, o oposto ocorreu com a RMSP em que o acréscimo foi quase nulo ou 3\%. Embora a variação 2006/1991 seja extremamente positiva, o mesmo não ocorre quando são observadas as participações da indústria no total das RA's, pois todas apresentam decréscimos em seus números. 
Campinas, por exemplo, em 1991 tinha 22\% de indústrias do total de estabelecimentos e em 2006 caiu para $16 \%$. O mesmo ocorrendo para as demais RA's inclusive a RMSP, ou seja, aqui se observa um padrão de declínio do número de indústrias em relação ao total em um mesmo ano.

TABELA 02 - NÚMERO DE ESTABELECIMENTOS COMÉ RCIO, INDÚSTRIA E SERVIÇOS POR RA'S DO ESP

\begin{tabular}{|c|c|c|c|c|c|c|c|c|c|c|c|c|}
\hline RA & & 1991 & $\begin{array}{l}\% \text { do } \\
\text { total }\end{array}$ & 1995 & $\%$ do total & 2000 & $\begin{array}{l}\% \text { do } \\
\text { total }\end{array}$ & 2005 & $\begin{array}{l}\% \text { do } \\
\text { total }\end{array}$ & 2006 & $\begin{array}{l}\% \\
\text { do } \\
\text { total }\end{array}$ & $\begin{array}{c}\operatorname{var} \% \\
2006 / 1991\end{array}$ \\
\hline & Total & 195.087 & 100 & 234.946 & 100 & 267.142 & 100 & 301.958 & 100 & 313.839 & 100 & 61 \\
\hline \multirow[t]{4}{*}{ RMSP } & Comércio & 77.136 & 40 & 92.865 & 40 & 105.296 & 39 & 125.660 & 42 & 130.255 & 42 & 69 \\
\hline & Indústria & 41.587 & 21 & 42.158 & 18 & 38.684 & 14 & 40.572 & 13 & 42.737 & 14 & 3 \\
\hline & Serviços & 76.364 & 39 & 99.923 & 43 & 123.162 & 46 & 135.726 & 45 & 140.847 & 45 & 84 \\
\hline & Total & 16.004 & 100 & 21.350 & 100 & 27.258 & 100 & 33.197 & 100 & 34.646 & 100 & 116 \\
\hline \multirow[t]{4}{*}{ SJC } & Comércio & 7.737 & 48 & 10.216 & 48 & 12.806 & 47 & 15.858 & 48 & 16.318 & 47 & 111 \\
\hline & Indústria & 2.114 & 13 & 2.298 & 11 & 2.342 & 9 & 2.670 & 8 & 2.913 & 8 & 38 \\
\hline & Serviços & 6.153 & 38 & 8.836 & 41 & 12.110 & 44 & 14.669 & 44 & 15.415 & 44 & 151 \\
\hline & Total & 19.519 & 100 & 24.058 & 100 & 30.772 & 100 & 38.856 & 100 & 40.556 & 100 & 108 \\
\hline \multirow[t]{4}{*}{ SOROCABA } & Comércio & 9.296 & 48 & 11.909 & 50 & 15.114 & 49 & 20.190 & 52 & 21.002 & 52 & 126 \\
\hline & Indústria & 3.742 & 19 & 3.986 & 17 & 4.485 & 15 & 5.122 & 13 & 5.397 & 13 & 44 \\
\hline & Serviços & 6.481 & 33 & 8.163 & 34 & 11.173 & 36 & 13.544 & 35 & 14.157 & 35 & 118 \\
\hline & Total & 52.640 & 100 & 69.318 & 100 & 87.197 & 100 & 108.482 & 100 & 112.893 & 100 & 114 \\
\hline \multirow[t]{3}{*}{ CAMPINAS } & Comércio & 23.042 & 44 & 31.262 & 45 & 39.415 & 45 & 51.877 & 48 & 53.572 & 47 & 132 \\
\hline & Indústria & 11.696 & 22 & 12.882 & 19 & 14.596 & 17 & 16.854 & 16 & 17.574 & 16 & 50 \\
\hline & Serviços & 17.902 & 34 & 25.174 & 36 & 33.186 & 38 & 39.751 & 37 & 41.747 & 37 & 133 \\
\hline
\end{tabular}

Fonte: Elaborado a partir de dados extraídos da Fundação SEADE

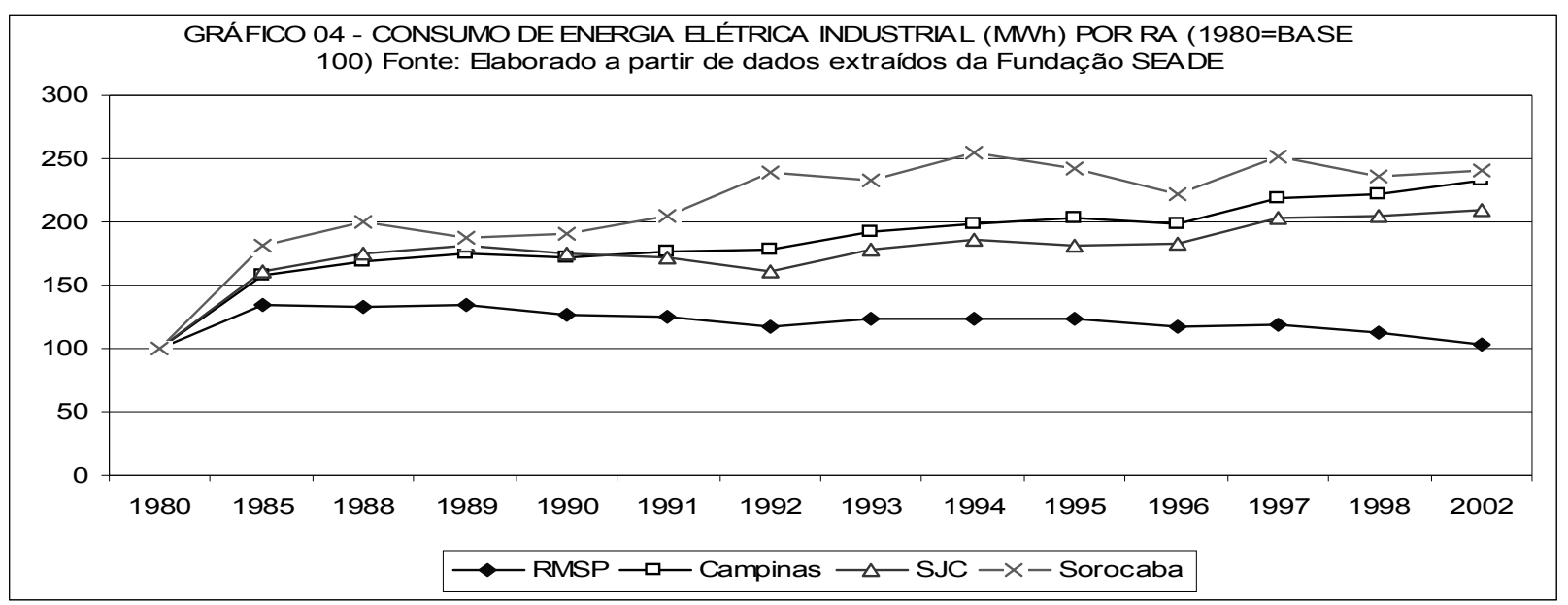


Outro indicador refere-se à quantidade de energia elétrica (em Megawats hora - MWh) consumida pela indústria, comércio e serviços de cada uma das regiões administrativas. Infelizmente os dados da Fundação SEADE apresentam o consumo de energia elétrica do comércio e dos serviços conjuntamente, já os da indústria são apresentados separadamente.

Assim, com o intuito de facilitar a compreensão dos inúmeros dados que são apresentados na tabela 03, optou-se em trabalhar com a variação percentual da série histórica, sendo o ano de 1980 igual a base 100 e os resultados apresentados na forma gráfica.

O gráfico 04 representa o consumo de energia elétrica da indústria nas RA's de Campinas, Sorocaba, São José dos Campos e RMSP sendo que o comportamento da curva de consumo da RMSP é declinante, o que corrobora com os dados até aqui apresentados com relação à desconcentração industrial. O mesmo indicador para as demais regiões apresenta-se com um comportamento ascendente, nas últimas duas décadas, opondo-se ao comportamento da RMSP.

\section{TABELA 03 - COMPARARATIVO DE CONSUMO DE ENERGIA ELÉTRICA POR REGIÃO ADMINISTRATIVA DO ESP}

MWh)

\begin{tabular}{|c|c|c|c|c|c|c|c|c|c|c|c|c|c|c|}
\hline RA's & 1980 & 1985 & 1988 & 1989 & 1990 & 1991 & 1992 & 1993 & 1994 & 1995 & 1996 & 1997 & 1998 & 2002 \\
\hline RMSP & 13.111 .624 & 17.599 .863 & 17.373 .418 & 17.590 .879 & 16.494 .846 & 16.403 .845 & 15.305 .058 & 16.140 .117 & 16.276 .755 & 16.259 .714 & 15.465 .569 & 15.595 .811 & 14.763 .534 & 13.495 .825 \\
\hline CAMPINAS & 4.140 .756 & 6.514 .132 & 6.968 .389 & 7.249 .295 & 7.148 .500 & 7.291 .790 & 7.344 .701 & 7.987 .361 & 8.228 .113 & 8.395 .100 & 8.206 .902 & 9.070 .828 & 9.214 .393 & 9.647 .569 \\
\hline SJC & 1.730 .122 & 2.784 .920 & 3.020 .768 & 3.149 .257 & 3.026 .027 & 2.973 .805 & 2.784 .580 & 3.069 .664 & 3.210 .863 & 3.125 .301 & 3.168 .272 & 3.512 .005 & 3.538 .704 & 3.610 .339 \\
\hline SOROCABA & 2.168 .233 & 3.928 .252 & 4.340 .816 & 4.068 .206 & 4.132 .522 & 4.429 .110 & 5.170 .397 & 5.042 .075 & 5.533 .178 & 5.258 .084 & 4.796 .822 & 5.465 .265 & 5.103 .578 & 5.220 .267 \\
\hline \multicolumn{15}{|l|}{ BASE 100} \\
\hline RMSP & 100 & 134 & 133 & 134 & 126 & 125 & 117 & 123 & 124 & 124 & 118 & 119 & 113 & 103 \\
\hline CAMPINAS & 100 & 157 & 168 & 175 & 173 & 176 & 177 & 193 & 199 & 203 & 198 & 219 & 223 & 233 \\
\hline SJC & 100 & 161 & 175 & 182 & 175 & 172 & 161 & 177 & 186 & 181 & 183 & 203 & 205 & 209 \\
\hline SOROCABA & 100 & 181 & 200 & 188 & 191 & 204 & 238 & 233 & 255 & 243 & 221 & 252 & 235 & 241 \\
\hline
\end{tabular}

Consumo de Energia Elétrica Comercial, de Serviços e Outras A tividades (Em MWh)

\begin{tabular}{|c|c|c|c|c|c|c|c|c|c|c|c|c|c|c|}
\hline RA's & 1980 & 1985 & 1988 & 1989 & 1990 & 1991 & 1992 & 1993 & 1994 & 1995 & 1996 & 1997 & 1998 & 2002 \\
\hline RMSP & 3.065 .886 & 4.061 .130 & 4.560 .209 & 4.784 .205 & 5.070 .194 & 5.230 .307 & 5.500 .823 & 5.845 .793 & 6.166 .613 & 6.878 .592 & 7.395 .489 & 8.013 .811 & 8.707 .152 & 9.317 .440 \\
\hline CAMPINAS & 433.019 & 614.853 & 726.840 & 768.334 & 835.972 & 898.805 & 932.228 & 994.773 & 1.061 .165 & 1.199 .502 & 1.337 .548 & 1.493 .553 & 1.638 .158 & 1.887 .650 \\
\hline SJC & 164.460 & 204.119 & 261.703 & 272.102 & 295.290 & 327.813 & 428.348 & 451.196 & 469.604 & 520.382 & 563.462 & 632.756 & 702.776 & 621.011 \\
\hline SOROCABA & 139.577 & 185.310 & 218.291 & 234.534 & 250.358 & 274.843 & 291.958 & 312.651 & 327.894 & 376.027 & 419.552 & 463.407 & 516.088 & 557.475 \\
\hline$\overline{\text { BASE } 100}$ & & & & & & & & & & & & & & \\
\hline RMSP & 100 & 132 & 149 & 156 & 165 & 171 & 179 & 191 & 201 & 224 & 241 & 261 & 284 & 304 \\
\hline CAMPINAS & 100 & 142 & 168 & 177 & 193 & 208 & 215 & 230 & 245 & 277 & 309 & 345 & 378 & 436 \\
\hline SJC & 100 & 124 & 159 & 165 & 180 & 199 & 260 & 274 & 286 & 316 & 343 & 385 & 427 & 378 \\
\hline SOROCABA & 100 & 133 & 156 & 168 & 179 & 197 & 209 & 224 & 235 & 269 & 301 & 332 & 370 & 3 \\
\hline
\end{tabular}

Fonte: Elaborado a partir de dados extraídos da Fundação 
O gráfico 05 , baseado nos dados de base 100 da tabela 03, apresenta o comportamento ascendente do consumo conjunto de energia elétrica do comércio e dos serviços no período de 1980 a 2002.

$\mathrm{Na}$ tentativa de mostrar graficamente o descolamento e comportamento existente entre os setores secundário e o terciário com relação ao consumo de energia elétricas das RA's foi elaborado o gráfico 6 . O comportamento do conjunto das curvas de consumo revela que a partir de meados da década de 90 a intensidade do consumo de energia elétrica é mais evidente no comércio e serviços de todas as RA's estudadas. Já para o conjunto de curvas de consumo de energia elétrica da indústria para a RMSP é declinante e para as demais RA's existe certa estabilidade.

Para a variável pessoal ocupado foi elaborada a tabela 04, na qual se observa crescimento do pessoal ocupado do setor terciário em todas as regiões. Na indústria, a situação é diferente, pois há um forte declínio do pessoal ocupado na RMSP e um declínio menos acentuado para as demais regiões durante toda a década de 90 e início dos anos 2000, a partir de então a inclinação da curva se inverte e passa a crescer o pessoal ocupado inclusive para a RMSP (ver gráfico 07), que em 2006 tinha mais de 1,1 milhões de trabalhadores na indústria (17\% do

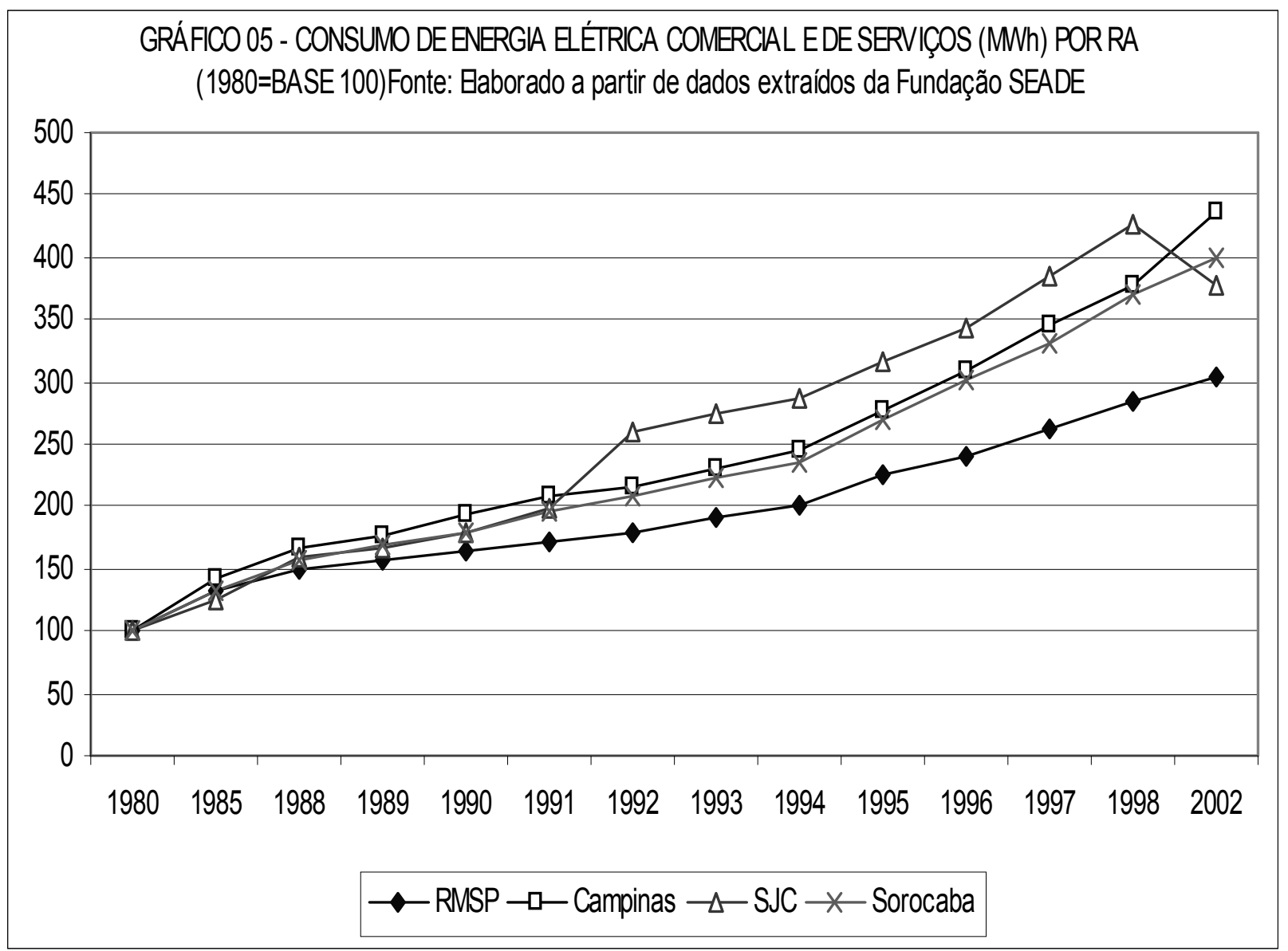




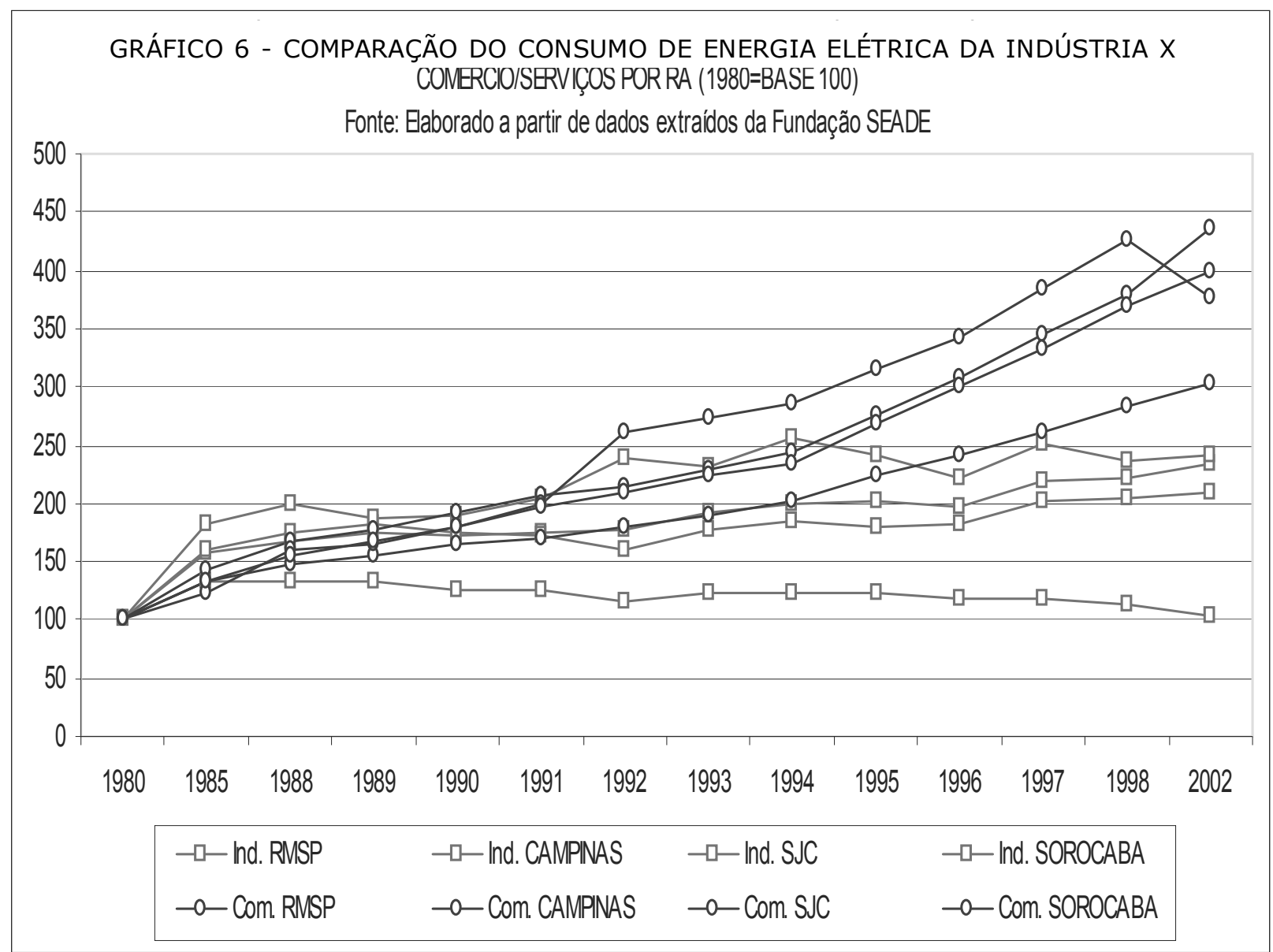

total da própria região) contra 517 mil (34\%) da RA de Campinas, 172 mil (32\%) de Sorocaba e $118 \mathrm{mil}(28 \%)$ de São José dos Campos.

A tabela 04 ainda mostra que do total do pessoal ocupado da RMSP $11 \%$ estavam empregados no comércio no ano de 1991 e em 2006 esse percentual saltou para $17 \%$, este foi 0 comportamento do pessoal ocupado no comércio para todas as RA's. No ano de 2006 todas as regiões tiveram cerca de $20 \%$ do total de trabalhadores da própria região empregados no comércio.

A RMSP é a que mais emprega, em números relativos e absolutos, no setor de serviços frente às demais regiões analisadas em torno de 3,3 milhões de pessoas no ano de 2006. A RA de São José dos Campos possui quase a metade de seus trabalhadores empregados no setor de serviços, Campinas $39 \%$ e Sorocaba $37 \%$ para o ano de 2006 . De forma geral, o número de trabalhadores no setor de serviços foi ascendente no período analisado de 1991 a 2006.

Olhando-se mais detidamente para o percentual do total de trabalhadores da indústria de cada uma das regiões nota-se que, sob este critério de análise, houve um decréscimo do número de trabalhadores frente ao total em todas as regiões analisadas. 


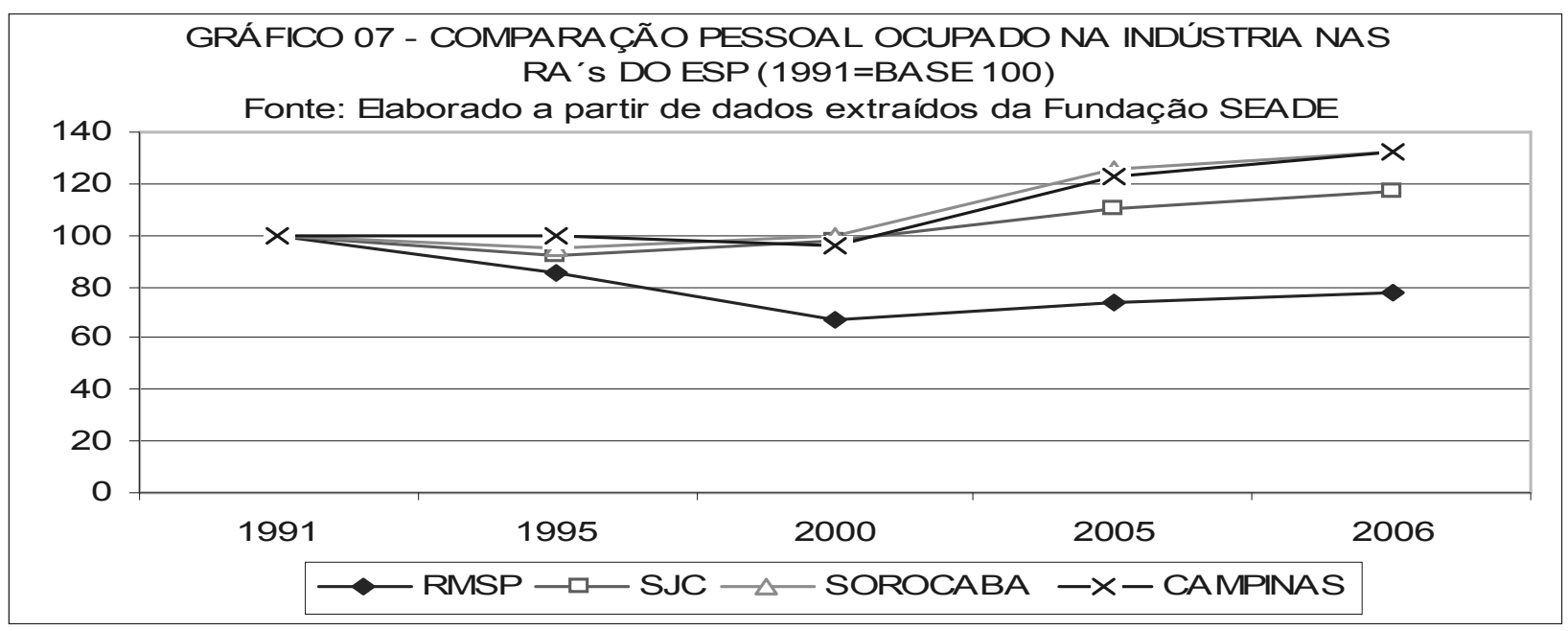

TABELA 04 - PESSOAL OCUPADO NA INDÚSTRIA, COMÉRCIO E SERVIÇOS POR RA 's DO ESP

\begin{tabular}{|c|c|c|c|c|c|c|c|c|c|c|c|}
\hline RA & & 1991 & $\begin{array}{l}\% \text { do } \\
\text { total }\end{array}$ & 1995 & \begin{tabular}{|l|}
$\%$ do \\
total
\end{tabular} & 2000 & \begin{tabular}{l|}
$\%$ do \\
total
\end{tabular} & 2005 & $\begin{array}{l}\text { \% do } \\
\text { total }\end{array}$ & 2006 & $\begin{array}{l}\% \text { do } \\
\text { total }\end{array}$ \\
\hline \multirow[t]{5}{*}{ RMSP } & Total & 4.749 .100 & 100 & 4.556 .620 & 100 & \begin{tabular}{|l|}
4.630 .539 \\
\end{tabular} & 100 & 5.426 .661 & 100 & 5.721 .804 & 100 \\
\hline & Comércio & 523.789 & 11 & 610.809 & 13 & 700.072 & 15 & 939.686 & 17 & 993.317 & 17 \\
\hline & Indústria & 1.459 .414 & 31 & 1.246 .834 & 27 & 981.731 & 21 & 1.073 .119 & 20 & 1.138 .619 & 20 \\
\hline & Serviços & 2.148 .116 & 45 & 2.421 .532 & 53 & 2.744 .178 & 59 & 3.211 .111 & 59 & 3.360 .404 & 59 \\
\hline & Soma & & 87 & & 94 & & 96 & & 96 & & 96 \\
\hline \multirow[t]{5}{*}{$\mathrm{SJC}$} & Total & 270.702 & 100 & 281.911 & 100 & 329.070 & 100 & 408.040 & 100 & 428.121 & 100 \\
\hline & Comérc io & 38.726 & 14 & 46.742 & 17 & 61.528 & 19 & 83.507 & 20 & 87.158 & 20 \\
\hline & Indústria & 101.321 & 37 & 92.868 & 33 & 98.627 & 30 & 111.323 & 27 & 118.256 & 28 \\
\hline & Serviços & 96.816 & 36 & 120.099 & 43 & 150.371 & 46 & 192.856 & 47 & 199.229 & 47 \\
\hline & Soma & & 87 & & 92 & & 94 & & 95 & & 95 \\
\hline \multirow[t]{5}{*}{ SOROCABA } & Total & 342.647 & 100 & 366006 & 100 & 425749 & 100 & 520922 & 100 & 542589 & 100 \\
\hline & Comércio & 43.030 & 13 & 52647 & 14 & 70800 & 17 & 99477 & 19 & 104570 & 19 \\
\hline & Indústria & 130.459 & 38 & 123824 & 34 & 130504 & 31 & 163745 & 31 & 172589 & 32 \\
\hline & Serviços & 124.645 & 36 & 140171 & 38 & 174865 & 41 & 189404 & 36 & 200394 & 37 \\
\hline & Soma & & 187 & & 187 & & 188 & & 187 & & 188 \\
\hline \multirow[t]{5}{*}{ CAMPINAS } & Total & 939.436 & 100 & 996949 & 100 & 1113933 & 100 & 1449929 & 100 & 1535936 & 100 \\
\hline & Comércio & 121.253 & 13 & 147514 & 15 & 196922 & 18 & 292950 & 20 & 304696 & 20 \\
\hline & Indústria & 390.459 & 42 & 388017 & 39 & 375528 & 34 & 479270 & 33 & 517113 & 34 \\
\hline & Serviços & 289.586 & 31 & 353552 & 35 & 445858 & 40 & 562834 & 39 & 599637 & 39 \\
\hline & Soma & & 85 & & 89 & & 91 & & 92 & & 93 \\
\hline
\end{tabular}

Fonte: Elaborado a partir de dados extraídos da Fundação SEADE 
Em 1991 a RMSP tinha $31 \%$ dos seus trabalhadores na indústria, em 2006 este percentual decai para $20 \%$. São José dos Campos tinha $37 \%$ em 1991 contra $28 \%$ em 2006. Sorocaba $38 \%$ e $32 \%$ e Campinas $42 \%$ e $34 \%$ para os anos de 1991 e 2006 respectivamente.

Estas análises expressam-se pelo ponto de vista de números relativos e de maneira absoluta houve incremento do número total de postos de trabalho para todas as regiões e setores, exceto para a indústria da RMSP que em 2006 empregava menos do que no ano de 1991.

O que demonstra a desconcentração industrial da RMSP e o aumento de postos de trabalho industrial nas regiões administrativas de Campinas, Sorocaba e São José dos Campos. Sendo que foi a RA de Campinas que mais se beneficiou com a desconcentração, pois no período de 1991 a 2006 teve um incremento na indústria de mais de 126 mil postos de trabalho ou $32 \%$. O aumento total de empregos, no período, foi de mais de 596 mil empregos ou $63 \%$ de incremento.

O trabalho de CANO (2007, pp. 216-236) traz uma série de informações sobre as regiões administrativas do estado de São Paulo. Especificamente para a região de Campinas o autor afirma que sua estrutura industrial é muito diversificada e concentra elevada participação estadual em quase todos os ramos de atividades como: combustíveis, borracha e plástico, cosmética e farmacêutica, transportes, máquinas e equipamentos, material eletrônico e de informática, alimentos e bebidas, papel e celulose, laranja industrial, têxtil entre outros.

A indústria da região de Campinas, desde a década de 1960, demonstra ser a mais vigorosa do interior do estado.

A região de São José dos Campos, segundo CANO (2007), detém uma estrutura muito diversificada e expressiva frente ao total do estado. Concentrada em ramos dinâmicos mais intensivos em capital e tecnologia e apresenta forte articulação com os principais centros metropolitanos do país.
Ainda segundo CANO (2007), a RA de Sorocaba apresenta uma estrutura produtiva muito diversificada, dos 29 ramos pesquisados pelo autor, 6 deles concentram $61,1 \%$ do VAF regional. A região apresenta uma tessitura indústrial semelhante a de regiões de forte aglomeração urbana e industrial, como as metropolitanas. O que pode explicar esse fenômeno é sua proximidade com a RMSP.

\section{Considerações Finais}

A RMSP sofreu forte transformação econômica, social e espacial nas últimas três décadas, com uma forte reversão na sua matriz econômica, deixando de ser uma metrópole eminentemente industrial para se tornar uma região de intenso comércio e prestação de serviços especializados. Apesar disso, ainda temcerca de 1,1 milhão de trabalhadores na indústria, o que demonstra que seu parque industrial ainda é bastante vigoroso.

A desconcentração industrial da RMSP teve efeitos que possibilitaram e intensificaram grandes mudanças sociais, econômicas e espaciais nas regiões administrativas de seu entorno. De forma generalizada pode-se afirmar que as regiões de Campinas, Sorocaba e São José dos Campos nas últimas três décadas sofreram substanciais alterações em sua estrutura socioeconômica e na organização espacial do seu território. Tornaram-se regiões com um parque industrial significativo e desenvolvedor de tecnologias de ponta e empregando considerável número de trabalhadores na indústria, algo em torno de 800 mil. O desempenho repete-se nos serviços e no comércio. Mas as sedes das principais empresas localizam-se, na sua maioria, na cidade de São Paulo e RMSP, assim como os serviços altamente especializados.

Toda essa mudança atraiu e exigiu uma melhor qualificação dos trabalhadores nas empresas localizadas nas regiões administrativas estudas, com claros reflexos na renda do trabalhador. O PIB per capita da população das regiões de Campinas e São José 
dos Campos é de aproximadamente 18 e 17 mil reais, números próximos aos $21 \mathrm{mil}$ da RMSP.

As alterações na organização espacial também são visíveis. Essas regiões reverteram parte de suas áreas agrícolas para distritos industriais, tecnificaram a produção e os espaços urbanos, hoje sediam grandes shoppings centers, edifícios comerciais, universidades, além de terem a melhor infraestrutura viária e de telecomunicações do país.

Portanto, o conjunto de indicadores analisados aponta, no seu conjunto, para uma desconcentração industrial do estado de São Paulo, significativamente na RMSP, por ser a região mais industrializada do estado. Porém, grande parte das indústrias que saiu da RMSP instalou-se nas RA's de Campinas, Sorocaba e São José dos Campos, mesmo assim a RMSP ainda mantém grande número de pessoal ocupada na indústria.

Com relação ao terciário, a RMSP ganha fortes investimentos e caracteriza-se por seus grandes espaços de comércio e prestação de serviços diversificados e altamente especializados. Em menor escala o mesmo ocorre nas RA's analisadas neste trabalho.

Este fenômeno de espraiamento da indústria e da riqueza a partir do maior pólo econômico e industrial do país em direção ao interior paulista é considerado uma forma de desconcentração e ao mesmo tempo de concentração industrial na área do entorno da RMSP e que guarda forte dependência com a cidade de São Paulo. Isso promoveu o desenvolvimento socioeconômico e consequente alteração espacial no território das cidades das regiões administrativas analisadas neste estudo.

\section{Notas}

${ }^{1}$ VTI - é um conceito definido pelo IBGE, que mede a diferença entre o valor bruto da produção industrial (VBPI) menos os custos de operações industriais (COI), onde o VBPI é a totalidade das transferências com vendas e estoques e COI são os custos com matéria-prima, combustíveis, energia, máquinas e equipamentos de produção, serviços de reparo e manutenção.
2 VAF - é um indicador econômico-contábil utilizado pelo Estado para calcular o repasse da receita do Imposto sobre Circulação de Mercadorias e Serviços (ICMS) e do Imposto de Produtos Industrializados (IPI), sobre exportação dos municípios. O tributo espelha o movimento econômico e, consequentemente, o potencial que o município tem para gerar receitas públicas.

\section{Referências Bibliográficas}

ARAÚJO, Maria de Fátima I. Reestruturação produtiva e transformações econômicas: região metropolitana de São Paulo. Revista Perspectiva. Vol. 15, no 1. São Paulo: Jan-Mar 2001. pp. 2030. 2001.

AZZONI, Carlos Roberto. O novo endereço da indústria paulista. Texto apresentado no $20^{\circ}$ Encontro Nacional da ANPUR - Associação Nacional de pesquisadores Urbanos. Nova Friburgo, mimeo, 1987.
AZZONI, Carlos Roberto. Economia de São Paulo: ainda a locomotiva? São Paulo: Revista São Paulo em Perspectiva. vol. 07, no 2, pp. 02-13, Abr-Jun 1993.

CANO, Wilson (et. al). Economia Paulista. Campinas: Alínea, 2007.

FUNDAÇÃO SISTEMA ESTADUAL DE ANÁLISE DE DADOS - SEADE. Informações socioeconômicas municipais. 
LENCIONE, Sandra. Reestruturação urbanoindustrial no estado de São Paulo: a região da metrópole desconcentrada. Revista Espaço e Debate. São Paulo: n. 38, pp. 54$61,1994$.

. O processo de metropolização do espaço: uma nova maneira de falar da relação entre metrópole e regionalização. In: SCHIFFER, Sueli (org.). Globalização e estrutura urbana. São Paulo: Hucitec/Fapesp, 2004.

NOBRE, Eduardo. Impactos da globalização econômica no complexo metropolitano expandido de São Paulo: possibilidades de ação. Disponível em: <http://www.usp.br/fau/docentes/ depprojeto/e nobre/impactos.pdf $>$. Acessado em: 05/12/2007.

Trabalho enviado em outubro de 2009

Trabalho aceito em dezembro de 2009 
